\title{
CORRESPONDENCE
}

\section{Research Reorganization}

SiR,-I would like to refer to your editorial entitled "Keeping a Straight Bat" (Nature, 231, 2; 1971) in which you refer to the various courses of action which are open to Mrs Thatcher, Minister for Education and Science, with respect to the support of research. You say, "Thus it may be possible enormously to increase the amount of research carried on within the academic section by lumping together those activities of the research councils - the MRC and the ARC as well as the Science Research Council-which are concerned with basic research". You go on to say that "specifically it should be possible to earn great benefits by incorporating many of the basic research units and stations maintained by the MRC and the ARC within universities and polytechnics". The idea of a close association between the research institutes and the universities is certainly not new and there has probably been as much movement in this direction in recent years as is possible when we realize that new buildings are often involved.

It is, however, a later remark in the editorial which I find much more disturbing: "But would not the merging of the research councils create too monolithic a central sponsor ?"... "The case for welding them together into a more efficient (because larger) organization for supporting academic research is, first, that the funds available for such work will fall short of real need in the years ahead and that a properly organized and more powerful research council would be able to make more rational decisions about priorities in research."

We have heard many different ideas about the reorganization of the research councils in recent months, ideas which if acted upon would have a profound effect on the organization of research in this country. I am sure that this feeling of uncertainty has already done much harm to the efficient working of the councils. The scientists themselves feel as if they were being buffeted in a storm not knowing from which direction the wind will blow next. The idea of a monolithic research council really seems the most stupid of all the current ideas. It is easy to predict that no sooner had it been set up than it would be necessary to sectionalize it along the lines of the present research councils. The idea that size necessarily brings efficiency is extremely naive. The Council for Scientific Policy should be capable of making rational decisions about priorities in research.

$$
\begin{aligned}
& \text { Yours faithfully, } \\
& \text { P. N. CAMPBELL }
\end{aligned}
$$

Department of Biochemistry,

9 Hyde Terrace,

Leeds LS2 $9 L S$

\section{Kidney Transplants}

SIR,-Your leading article "Nothing Much to Report on Transplants" (Nature, 231,274 ; 1971) drew attention to the need for centres to coordinate the matching and distribution of cadaver kidneys so that patients needing renal transplants may receive as closely matched kidneys as possible. Your readers were given the impression that nothing is being done about this in Britain. In fact two centres have been working actively for the past two years, one in Newcastle and the other in London. Each provides a 24 hour service with a medically qualified immunologist backed up by a computerized register of recipient information. Each centre coordinates the typing and distribution of cadaveric kidneys to and from a group of collaborating hospitals. The centres in Newcastle and London work closely and amicably together and with the comparable organizations on the continent-Eurotransplant, Scandia-transplant and France-transplant.

The London Transplant Group began in 1968 as a collaboration between three hospitals: in 1970 there were 15: today there are 22. At first the pool of patients awaiting transplant was only 30 : in 1970 it had risen to 170: today it stands at 400 . By June 1970 the LTG had arranged 85 transplants: a year later this number had risen to 220 .

By increasing the size of the recipient pool, it has been possible to improve the tissue matching. In 1969 less than one in ten transplants had as many as three of their four HL-A antigens in common. In the first 6 months of 1971 , no less than $61 \%$ of all transplants arranged by the LTG had three or four HL-A antigens in common, whilst in sixteen transplants all four antigens were identical, a closeness of matching not yet approached by any similar organization in Europe or America.

The improvement in matching has been reflected in the survival of kidneys after transplantation. If we exclude the kidneys which never survive the grafting operation, we find that 9 months later all those with $4 / 4$ antigens in common are still functioning and $88 \%$ of those with $3 / 4$ matches, whereas only $67 \%$ and $57 \%$ of those in two less well matched categories are still surviving. The differences between the best ( $3 / 4$ and $4 / 4)$ and worst matches are highly significant.

We are not surprised that your leading article made no reference to either the Newcastle or the London centres. Neither of them gets any official approval or financial support from the Department of Health and Social Security. Quite the reverse: far from supporting either enterprise, the Department has recently decided to set up an entirely new centre at Bristol and destroy the existing organizations. The new centre, for which an expensive computer has been allocated, is to concern itself only with the British Isles. This is the reverse of progress. On the one hand we are likely to face a prolonged interregnum during which our patients will be deprived of well matched kidneys, since the necessary experience and know-how to run such a coordinating centre does not spring up overnight.

On the other hand, the cooperation with Europe and Eire which has been built up so laboriously, and which has already borne such fruit, is to be deliberately terminated. What is required now is not a new National Centre: like the existing regional network, it must surely be superseded by a European one. This should be the real object of the Department and, until it can achieve it, it would be grossly wasteful not to support existing centres in Newcastle and London.

\section{Yours faithfully, \\ J. P. BLANDY \\ H. FESTENSTEIN}

The London Hospital,

Whitechapel,

London $E 11 B B$

\section{Scientologists}

SiR,- I could scarcely believe my eyes when I read your Washington Correspondent's report on the US Food and Drug Administration's battle with the scientologists (Nature, 231, 485; 1971). The extreme vigour with which the FDA carried out its campaign against Wilhelm Reich might well be thought overdone, 